\section{FAVORECER UNA LECTURA DEL MUNDO}

Osvaldo Nildo Balmaceda Neyra*

\author{
TARGINO, M. das G.; SILVA, E. M. P. \\ de A.; SANTOS, M. F. P. dos (Org.). \\ Alfabetização e letramento: múltiplas \\ perspectivas. Teresina: EDUFPI / UFPI / \\ UAB / CEAD, 2017. 238 p. Disponível \\ em: \\ <http://educapes.capes.gov.br/handle/ \\ capes/ I74662>. Acesso em: I5 ago. 2017.
}

\begin{abstract}
* Profesor Doctor en Ciencias Pedagógicas de la Facultad de Artes y Letras de la Universidad de La Habana, Cuba. Presidente de la Asociación de Lingüistas de Cuba. Exdirector de posgrado del Ministerio de Educación Superior de la República de Cuba.

E-mail: osbalneyra@yahoo.es.
\end{abstract}

\section{A} nte el título "ALFABETIZAÇÃO E LETRAMENTO: MÚLTIPLAS PERSPECTIVAS", es evidente que se hace más difícil la existencia social sin el adecuado conocimiento de la lectura y la escritura. Vivimos en sociedades letradas, esto es, sociedades donde la vida transcurre entre letras y números. Siglos atrás, cuando los libros y todo tipo de documentos se escribían solo a mano, el dominio de la lectura y la escritura era privilegio de muy pocas personas: sobre todo de las pertenecientes al clero y la nobleza. La invención de la imprenta de tipos móviles, a fines del siglo $\mathrm{XV}$, no solo debió despertar el interés de poder descifrar los signos de la escritura - sobre todo alfabética -, sino que la alfabetización se fue convirtiendo en una de las primeras necesidades para la subsistencia y el mejoramiento de la calidad de vida, de manera que hoy el índice de personas que saben leer y escribir es un indicador esencial para medir el desarrollo socioeconómico de los países.

El analfabetismo está fuertemente asociado a la pobreza, a la falta de oportunidades, a la desigualdad y la exclusión. Esta situación se manifiesta al comparar la cantidad de personas analfabetas que hay en los países desarrollados y en los subdesarrollados, así como entre hombres y mujeres; por ejemplo, en los países de ingresos bajos y medianos bajos 115 millones de jóvenes de 15 a 24 años no saben leer, y se calcula que alrededor del $61 \%$ de esos jóvenes son mujeres. En el África subsahariana casi la mitad de las mujeres son analfabetas.

La Organización de las Naciones Unidas para la Educación, la Ciencia y la Cultura (UNESCO) ha hecho enormes esfuerzos y ha puesto en marcha proyectos para erradicar el analfabetismo de la faz del planeta o reducirlo a cifras insignificantes; pese a ello, en el mundo todavía existen unos 758 millones de personas mayores de 15 años que no saben leer ni escribir, de acuerdo con uno de los últimos reportes de ese organismo internacional.

La UNESCO considera que los propósitos de una educación para todos, proyectados para el 2030, apenas serán cumplidos con medio siglo de retraso, teniendo en cuenta que la educación primaria universal solo podrá alcanzarse en el 2042. Para cumplir con los objetivos de la UNESCO, numerosos gobiernos han logrado aumentar las tasas de escolarización, sobre todo en la enseñanza elemental o básica, pero al estar generalizada la educación de mala calidad, un significativo número de estudiantes no logra vencer los objetivos trazados para los diferentes niveles, por lo que se incrementan las deserciones escolares y con ello las posibilidades de estancarse o perderse habilidades presuntamente adquiridas en la escuela, 
entre ellas las de leer y escribir. A esta situación se le añade que el presupuesto asignado a la educación de jóvenes y adultos no rebasa el $4 \%$ en muchos de los países que afrontan estos problemas. Este panorama pudiera empeorar debido al incremento de los flujos migratorios, compuestos mayoritariamente por niños y jóvenes que no han completado los estudios de nivel elemental quienes, indudablemente, pasarán a engrosar las legiones de analfabetos.

En el año 1961 Cuba, un pequeño país del tercer mundo, emprendió una campaña de alfabetización con la cual logró alfabetizar a más de 700000 personas, con lo que consiguió reducir el índice de analfabetismo a 3,9\% de su población total en solo un año. Fue un esfuerzo colosal que involucró a más de 300 mil alfabetizadores, entre ellos 100 mil jóvenes que se trasladaron hasta los hogares donde hubiera un analfabeto, sin importar cuán apartados estuvieran. Después de ese éxito, la tarea consistiría en que las personas alfabetizadas continuaran estudiando, aspiración que se logró en buena medida.

A partir de esta experiencia, muchos países de América Latina emprendieron proyectos encaminados a eliminar el analfabetismo, por lo que hoy este continente ha mejorado los índices de alfabetización; sin embargo, países del África subsahariana, Asia del Sur y del Oriente Medio registran altas tasas de analfabetismo que, en algunos casos, superan el 70\% de sus poblaciones.

Sin embargo, no basta con solo aprender a leer y escribir; es necesario que la persona haga un uso eficiente de la lectura y de la escritura; es decir, que sus habilidades de leer y escribir se incorporen a su vida cotidiana, a la práctica social. Los pedagogos brasileños han encontrado una palabra para diferenciar un estado del otro; esto es, limitarse a la decodificación de signos escritos como algo bien distinto de poder hacer de la lectura un pleno ejercicio de comprensión e interpretación, que le permita al individuo apropiarse de otros conocimientos y desempeñarse en la complejidad de la sociedad contemporánea: letramento.

La comunidad hispanohablante no dispone de una palabra para designar ese concepto; por lo general al sujeto que no posee las habilidades de lectura y escritura tal como se describen en el párrafo anterior, se le califica de "analfabeto funcional." Confieso que conocí esa palabra gracias a unos profesores brasileños que participaron en un congreso sobre educación en Cuba hace ya varios años, por ello me congratulo al tener ante mis ojos un manojo de artículos que abordan con rigor científico la noble tarea de continuar favoreciendo el aprendizaje de la persona alfabetizada a través de la investigación misma y de propuestas para emplear herramientas y metodologías, desde las más convencionales hasta las más novedosas como las tecnologías de información y de comunicación e Internet.

Este libro que el lector ahora tiene en sus manos "Alfabetização e Letramento: múltiplas perspectivas" es iniciativa del Centro de Educación Abierta a Distancia (CEAD) y de la Universidad Abierta del Brasil (UAB) / Universidad Federal de Piauí (UFPI) y recoge una interesante obra colectiva coordinada por las profesoras Maria das Graças Targino, Evana Mairy Pereira de Araújo Silva y Maria Fátima Paula dos Santos. Todas suman en su currículo una abundante y pertinente producción intelectual, lo que asegura la calidad en la selección de los textos y la factura de la edición. Todos los autores son profesores y la mayoría está especializada en el área de alfabetización y letramento, gracias al Curso de Especialización en Alfabetización y Letramento ofrecido por CEAD hasta diciembre de 2016.

En las siguientes páginas se despliega toda una original variedad en el tratamiento del tema que nos ocupa: la alfabetización y el letramento. El lector descubrirá trabajos que investigan cómo emplear procederes diversos, recursos y herramientas didácticas para la formación de lectores capaces, no solo de jóvenes y adultos, también de niños en la escuela, como las cantigas de roda, la poesía y la literatura fantástica, que propician múltiples lecturas; llaman la atención abordajes infrecuentes en el tratamiento de este tema, como la exclusión social, la desmarginalización del grafito o grafitis (pichação) y el prejuicio lingüístico en la escuela. No menos importantes resultan los artículos dedicados al letramento digital y su relación con la exclusión digital y social de jóvenes y adultos $\mathrm{y}$, por supuesto, no podría faltar en un texto de esta naturaleza la inexcusable relación entre la escuela y la familia no solo para la formación de buenos lectores, sino para la formación de un ciudadano que pueda, como propuso Paulo Freire, hacer una lectura del mundo. 